Brit. J. industr. Med., 1952, 9, 50.

\title{
VANADIUM POISONING FROM CLEANING OIL-FIRED BOILERS
}

\author{
BY \\ N. WILLIAMS \\ From the London Transport Executive \\ (RECEIVED FOR PUBLICATION MAY 1, 1951)
}

The vanadium content of crude oil ash varies considerably according to its source. It may be as high as $45 \%$ in Venezuelian and $14 \%$ in Iranian crude oil or as low as a trace in Wyoming crude oil and none in the Pennsylvanian product (Dunstan, 1938). As fuel oils are residual oils left after the distillation of the more volatile hydrocarbons, they will contain a higher proportion of vanadium than the corresponding crude oils. Thus an oil with an ash content of $0.1 \%$ containing $40 \%$ of vanadium as $\mathrm{V}_{2} \mathrm{O}_{5}$ would produce $1 \mathrm{lb}$. of vanadium pentoxide for 11 tons of oil burnt. A significant proportion of the vanadium accumulates in the gas passages of boilers. This paper describes the symptoms and clinical findings in men cleaning oil-fired boilers, and sets out evidence that vanadium was responsible.

After the recent war a generating station was partly converted to burning fuel oil owing to shortage of coal. After cleaning the oil-fired boilers the men noticed symptoms which they associated with the work. Before this conversion there had been no complaints from the boiler-cleaners of any harmful effect on their health.

The boilers are probably the largest oil-fired land installations in this country, each boiler consuming about 150 tons of fuel oil per week. The lower part of the boiler, into which is sprayed the atomized oil, is known as the combustion chamber, which is lined by refractory fire-bricks, and on its rear and side walls are the vertical generating tubes. In the upper part of the boiler are more generating tubes interspersed between which are the superheater tubes. Considerable quantities of petroleum soot are deposited in both the combustion and superheater chambers.

Each boiler requires cleaning once a year in order to maintain its efficiency, and it has been found necessary at these times to renew the fire-brick lining. It takes a gang of eight men about five days to clean a boiler, after which the bricklayers enter to dismantle the fire-brick walls and build new ones.

The boiler cleaning methods in use when the investigation began produced large quantities of dust. The combustion chamber was cleaned by brushing the soot off the walls, and the boiler tubes by tapping with a rod, the soot falling off as a result of the vibration. In the superheater chamber the banks of tubes had to be cleaned by a compressed air jet from a nozzle, as it was difficult to reach them by other means (Fig. 1). Dismantling the fire-brick walls also produced dust, and the bricklayers complained of similar, though less severe, symptoms than those described by the boilercleaners (Fig. 2). The scaffolders, who are the first to enter the boiler in order to erect the platforms from which the cleaners work, have had symptoms similar to those of the bricklayers, but the cases reported in this paper are all boiler-cleaners.

\section{Methods of Analysis}

The vanadium content of the urine samples was determined by a colorimetric method described by Sandell (1950) in which sodium tungstate is used. The method was checked by estimating vanadium in the urines of men not exposed to petroleum soot, none being detected in these samples, and urines to which known quantities of ammonium metavanadate were added. It was found that the method was accurate in determining quantities as low as $0.02 \mathrm{mg}$. per specimen. Samples of dust were collected from different parts of the boilers during cleaning operations. Measured volumes of dustladen air were drawn through distilled water contained in an aspirator packed with Lessing rings, a guard aspirator also being fitted as a precaution. Three separate samples of $3 \cdot 7,4 \cdot 5$, and $6 \cdot 8 \mathrm{cu}$. $\mathrm{m}$. were collected, the air being passed at about $7 \cdot 1 \mathrm{cu}$. 
FIG. 1.-Boiler-cleaners demonstrating methods of dislodging soot from generator and superheater tubes. The one on the left is using a compressed air lance, and on the right the cleaner is tapping the tubes with a right
rod.

FIG. 2.-Bricklayers dismantling a fire-brick wall. The man on the right is spraying the bricks with water.

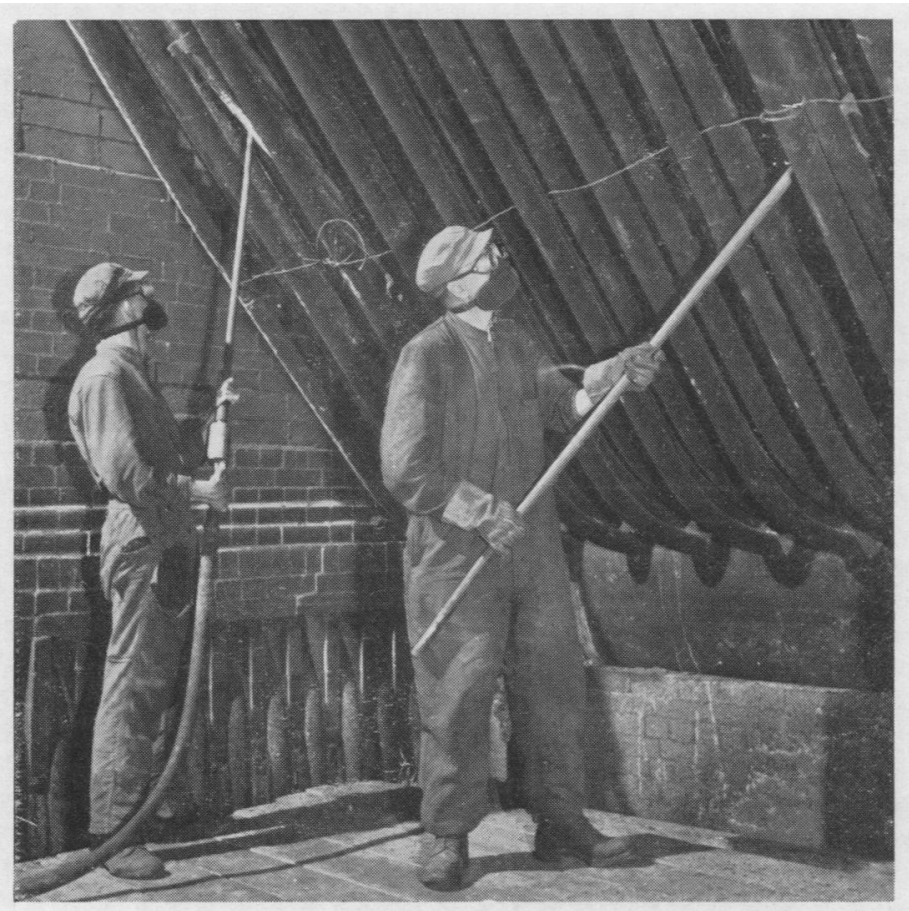

Fig. 1

Fig. 2

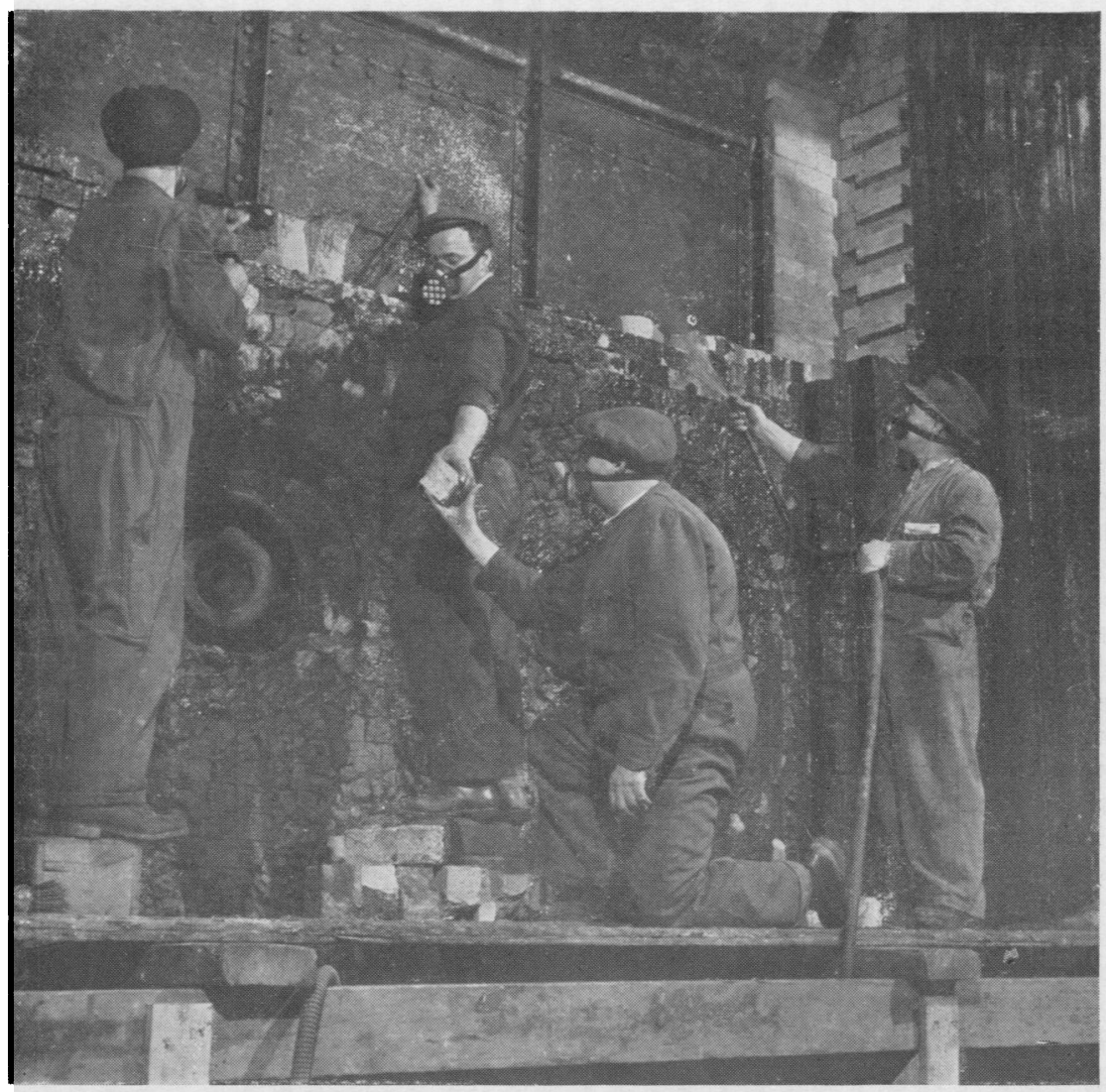


m. per hour. Vanadium was estimated both in the resultant solution and suspended solids. Thermal precipitator samples were used to estimate particle size and concentration. The microscope technique involved the use of both $4 \mathrm{~mm}$. and $2 \mathrm{~mm}$. objectives. Particles counted ranged from 11 to 0.44 microns with the $4 \mathrm{~mm}$. objective, and 4 to 0.15 microns using the $2 \mathrm{~mm}$. objective.

\section{Symptomatology}

Boiler-Cleaners' Complaints.-All the eight men engaged on this work complained of symptoms associated with cleaning oil-fired boilers. The first symptoms usually occurred between half and one hour after starting work, but in some cases were delayed for 12 hours. They consisted of rhinorrhoea, sneezing, watering of the eyes, soreness of the throat and behind the sternum. This group of symptoms can be described as the primary symptoms, the secondary ones appearing after a period of six to 24 hours. They were dry cough, wheezing, severe dyspnoea causing the man to rest after climbing a 20-foot ladder, lassitude, and depression with a disinclination to follow the usual evening activities. A greenish-black coating developed on the tongue which faded two or three days after contact with petroleum soot was over. Some of the men noted that the cough became paroxysmal and productive.

These symptoms continued while at work and only became less severe three days after ceasing work. In one man the wheezing and dyspnoea persisted for over a week, but none noticed any permanent ill-effects.

Personal Observations.-I entered one of the oilfired boilers while it was being cleaned and remained there for about one hour to obtain first-hand experience of the symptoms. Rhinorrhoea, sneezing, and watering of the eyes occurred within 15 minutes. Three hours later the secondary symptoms began to develop : dry cough, wheezing, dyspnoea, and soreness behind the sternum. Cough and wheezing continued throughout the night disturbing sleep. During the next day dyspnoea became more intense, it being impossible to walk at even a moderately brisk pace on the level. Climbing 30 stairs necessitated a short period of rest before continuing. There was a general feeling of depression, and it was difficult to take the usual interest in work. Cough became productive after the second day. The bronchospasm was not relieved by " benadryl" but ephedrine and stramonium gave some relief. The dyspnoea had disappeared by the end of one week, but the cough persisted for a further week. It had at one time been suggested that the symptoms were due to sulphur dioxide, but the absence of the characteristic smell and the delay in the onset of the symptoms excluded this possibility.

\section{Clinical Reports}

All eight boiler-cleaners were examined beforc and after work, that is after exposures lasting approximately one week. It was obvious from a knowledge of the men's previous personalities that they were in low spirits, looked tired, listless, and pale. One man complained that coughing had been sufficiently severe to produce vomiting. Another noticed that the tips of his cigarettes turned green.

Examination of the tongue revealed a coating on the dorsum varying from greenish-black to greenish-yellow. It was not possible to remove the discoloration by scraping. In two of the men there were signs of generalized bronchospasm and bronchitis. Two other men had developed râles in the right axillary region. Cardiac examination revealed no abnormality. In two men slight tremor of the hands developed.

$X$-ray films of the chest, electrocardiograms, and routine examination of the urine for albumin, sugar, and blood revealed no abnormality.

\section{Case Reports}

Case 1.-This man, aged 38, had been a boiler-cleaner from 1947 to 1949 . He was examined after five days' cleaning on an oil-fired boiler. He complained of sneezing within two hours of starting work and developed a cough the same evening. He was dyspnoeic the next day on ladder climbing, was depressed, and felt tired. $\mathrm{He}$ noticed that cigarette tips turned green. Examination revealed a greenish-black coating on the tongue, many high-pitched rhonchi throughout the chest, and râles in the right axillary region. Blood pressure was $110 / 70$ (pre-exposure 138/65). A radiograph of the chest revealed no abnormality. Urine analysis showed $0.08 \mathrm{mg}$. vanadium in $210 \mathrm{ml}$. urine passed during the day and $0.02 \mathrm{mg}$. vanadium in an early morning specimen of $297 \mathrm{ml}$.

Case 2.-Aged 40, he had been a boiler-cleaner from 1946 to 1949 . He was examined after two days' exposure. He developed rhinorrhoea and sneezing within three hours of starting work and a dry cough the same evening. He felt drowsy, and was dyspnoeic on climbing stairs. Examination revealed a yellowish-green coating on the tongue, scattered rhonchi over both lungs with râles at both bases. Blood pressure was 110/75 (pre-exposure $140 / 95$ ). A radiograph of the chest was normal. No vanadium was detected in the urine.

Case 3.-This man, aged 32, had been a boiler-cleaner from 1947 to 1949. He was examined two days after ceasing two days' work in an oil-fired boiler. He developed rhinorrhoea and sneezing half an hour after starting work. He noticed tightness of the chest the same evening, and felt depressed. Next day dry cough began, 
and he became dyspnoeic and orthopnoeic. He had to sit down after climbing a flight of stairs. Examination revealed a yellowish-green coating on the tongue. A fine tremor of the hands was evident. No physical signs were detected in the chest. Blood pressure was $120 / 82$ (pre-exposure 145/90). A radiograph of the chest was normal. No vanadium was detected in the urine.

Case 4.-Aged 43, he had been a boiler-cleaner from 1946 to 1949 . He was examined after five days' exposure. He developed rhinorrhoea and sneezing within half an hour of starting work and later soreness of the throat and chest. Dry cough started later the same day. Next day he became dyspnoeic and had to rest after climbing a ladder. He felt depressed. By the fifth day cough had become paroxysmal and induced vomiting. Examination revealed a pale green coating on the tongue. No physical signs were detected in the chest. Blood pressure was $105 / 70$ (pre-exposure 128/80). A day sample of $230 \mathrm{ml}$. urine contained a trace of vanadium.

Case 5.-This man, aged 39, had been a charge hand boiler-cleaner from 1946 to 1949 . He was examined after five days' exposure. No symptoms appeared on the first day, but rhinorrhoea and cough developed on the second day, with some wheezing and a tight feeling across the chest. Cough was productive on the third day. The patient was dyspnoeic on climbing stairs, and felt listless. Examination revealed that he was paler than normal ; the tongue was light green posteriorly. No physical signs were detected in the chest. Blood pressure was $110 / 65$ (pre-exposure 125/80). A radiograph of the chest was normal. No vanadium was detected in the urine.

Case 6.-The patient was aged 35 and had been a boiler-cleaner from 1948 to 1949 . He was examined four days after ceasing boiler-cleaning, an operation lasting three days. He developed rhinorrhoea and cough towards the end of the first day, but had no wheezing. He lacked concentration. Cough ceased two days after exposure ended. Examination showed a pale yellow coating over the tongue and a few râles in the right axilla. Blood pressure was 110/70 (pre-exposure 150/80). A radiograph of the chest was normal. The urine, $152 \mathrm{ml}$., contained a trace of vanadium.

Case 7.-This man, aged 39, had been a boiler-cleaner from 1948 to 1949 . He was examined after five days' exposure. He developed sneezing and rhinorrhoea within six hours of starting work. Cough began next day and soon became productive. He was dyspnoeic on climbing a ladder and had to rest at the top. Examination showed a greenish-black coating on the tongue, and a fine tremor of the hands. No physical signs were detected in the chest. Blood pressure was $150 / 90$ (preexposure 150/90). A radiograph of the chest was normal. No vanadium was detected in the urine.

Case 8. - The last patient, aged 26 , had been a boilercleaner from 1947 to 1949 . He had had occasional cough cleaning coal-fired boilers. He was examined after five days' exposure. He developed rhinorrhoea, sore throat, and cough within one hour of starting work, and felt a tightness of the chest the same evening. .He was dyspnoeic next day and had to rest after climbing a ladder. He noticed a bitter taste in the mouth, and felt depressed. Examination showed a thick, dark green coating on the tongue. No physical signs in the chest were detected. Blood pressure was 120/75 (pre-exposure 130/90). A radiograph of the chest was normal. No vanadium was detected in the urine.

\section{Vanadium in Urine}

Specimens over a period of 24 hours, on the last day of working at boiler cleaning, were collected from each man, precautions being taken to prevent contamination by dust from the clothes and hands.

The largest amounts of vanadium were detected in the urine samples from Case $1(0.4 \mathrm{mg}$. and 0.07 mg. per litre). It is interesting to note that this man was regarded clinically as being the most severely affected.

Traces were found in the specimens of Cases 4 and 6 , one of whom had severe symptoms and the other mild. Vanadium was not detected in the urine of the remaining cases.

\section{Atmospheric Dust}

Table 1 gives the average results obtained from two thermal precipitator samples taken in the superheater. On the average the numerical concentration of dust particles not exceeding 11 microns in diameter was 3,526 particles per $1 \mathrm{ml}$. of air, and of these $93.6 \%$ did not exceed 1 micron in size. Although there was such a numerical preponderance of fine particles these accounted for only a small proportion of the weight of dust in the air. The weight concentration of particles within different size ranges has been computed on the assumptions that the particles are spherical in shape, and that the dust has a specific gravity of 2 . The results of these calculations are shown in the fourth column of Table 1, where it is seen that the mass concentration of dust below 1 micron in size was only $0.36 \mathrm{mg}$. per cu. m. In the last column of Table 1 the weight concentrations of particles of various sizes are shown as percentages of the total estimated weight concentration of particles not greater than 11 microns. It should be remembered, however, that the estimate of the total weight concentration $(12.3 \mathrm{mg}$. per cu. m.) of particles of this range of size can give no indication of the weight concentration of the whole dust when there are present many particles greatly exceeding 11 microns in diameter. That is made clear by comparing the weight concentrations in Table 1 with those in Table 2 which gives the results of the three samples taken from boilers during cleaning operations, by aspirating air through distilled water (Table 2). The range of particle size of the vanadium dust is not known but 
TABLE 1

THERMAL PRECIPITATOR SAMPLES TAKEN FROM SUPERHEATER DURING CLEANING OPERATION

\begin{tabular}{c|c|c|c|c}
\hline $\begin{array}{c}\text { Diameter of Particles } \\
(\mu)\end{array}$ & $\begin{array}{c}\text { Number of Particles } \\
\text { (per 1 ml. air) }\end{array}$ & $\begin{array}{c}\text { Numerical Concen- } \\
\text { tration of Particles } \\
(\%)\end{array}$ & $\begin{array}{c}\text { Weight Concentration } \\
\text { of Particles } \\
(\mathrm{mg} \text {. per cu. m.) }\end{array}$ & $\begin{array}{c}\text { Weight Concentration } \\
\text { of Particles } \\
(\%)\end{array}$ \\
\hline $0 \cdot 15-1.0$ & 3,300 & 93.6 & 0.36 & 2.9 \\
$1.0-5.5$ & 217 & 6.14 & 7.09 & $33 \cdot 3$ \\
$5 \cdot 5-11$ & 9 & 0.26 & 7.85 & 63.8 \\
\hline
\end{tabular}

TABLE 2

ANALYSIS OF DUST FROM BOILER DURING CLEANING

\begin{tabular}{|c|c|c|c|c|c|c|}
\hline \multicolumn{4}{|c|}{ Sampling Point } & \multirow{2}{*}{ 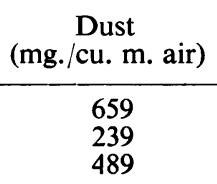 } & \multirow{2}{*}{$\begin{array}{c}\begin{array}{c}\text { Vanadium } \\
\text { (as \% of dust) }\end{array} \\
\begin{array}{c}6 \cdot 1 \\
7 \cdot 2 \\
12 \cdot 7\end{array}\end{array}$} & \multirow{2}{*}{$\begin{array}{c}\begin{array}{c}\text { Vanadium } \\
\text { (mg./cu. m. air) }\end{array} \\
\begin{array}{c}40 \cdot 2 \\
17 \cdot 2 \\
58 \cdot 6\end{array}\end{array}$} \\
\hline $\begin{array}{l}\text { Superheater chamber } \ldots \\
\text { Superheater chamber } \\
\text { Combustion chamber }\end{array}$ & $\begin{array}{l}\cdots \\
\cdots \\
\cdots\end{array}$ & $\begin{array}{l}\cdots \\
\cdots \\
\cdots\end{array}$ & $\begin{array}{l}\cdots \\
\cdots \\
\cdots\end{array}$ & & & \\
\hline
\end{tabular}

when advising on the use of suitable respirators it is safer to assume that the smallest dust particles contain vanadium.

\section{Preventive Measures}

Efforts were made to prevent or reduce the amount of the dust produced, but the main problem was to prevent the inhalation of the dust by the boiler-cleaners.

It was found that a large part of the boiler could be cleaned by an operator standing outside the boiler at the manhole using a lance several feet long, from which a jet of compressed air boosted to a very high pressure was ejected. The soot was drawn away from the operator and up the flue to the outside atmosphere by the induced draught fan. As certain parts of the boiler could not be reached by this method, men wearing dust respirators (Mark IV, Siebe Gorman), a type approved for use where there is a silicosis hazard, entered the boiler itself in order to complete the cleaning. When the induced draught fan could be used to advantage this was switched on.

Much soot dust was produced when the firebrick walls were dismantled and a water spray was therefore used on the bricks as they were being dislodged. A tarpaulin was stretched over the top of the combustion chamber to prevent soot particles, dislodged from the boiler tubes by vibration, falling from the superheater chamber into the combustion chamber where men were working.

Two boilers have been cleaned using these methods without a single complaint of symptoms from the boiler-cleaners, scaffolders, or bricklayers.

More recently, two boiler-makers and two brick- layers have been engaged on repairs in a boiler which had not been previously cleaned. They wore their respirators only when it appeared to them that there was dust in the atmosphere and it is not surprising that they developed minor symptoms of vanadium intoxication. The vibration of the repair work must have caused a small amount of soot to get into the air of the combustion chamber. It has therefore been recommended that all men entering boilers which have not previously been completely cleaned should wear suitable respirators.

\section{Discussion}

A search of the literature has failed to disclose any reference to symptoms caused by this type of work, although it has been known for many years that petroleum and petroleum soot contained vanadium in varying proportions. Respiratory symptoms of vanadium poisoning among workers extracting vanadium from petroleum soot, obtained from the boilers of oil-fired liners, were described by Wyers (1946). Information obtained from a boiler-cleaning company revealed that they have paid increased wages since 1924 for men cleaning oil-fired boilers. The reasons for this have been obscured by time, but it would appear that there were two possible reasons: the dirtier nature of the petroleum soot and the unpleasant respiratory symptoms experienced. The management stated that the men still complained of a wheezing of the chest, but medical advice on this, as an industrial problem, had never been sought. They had, however, provided the men with a light mask with a cotton wool filter. 
Sjöberg (1949) recorded four cases of bronchopneumonia, one of lobar pneumonia, and one of pleurisy among workers exposed to vanadium dust. The sick records of the boiler-cleaners over the last two years were examined, but they revealed no significant increase in sickness absence from any cause. This would appear to be in accordance with the views of Symanski (1939) who, in a very full account of vanadium poisoning, concluded that the work should be intermittent in order to allow recovery from adverse effects. In the present series of cases the system of working had, in fact, produced these conditions as the men work on oil-fired boilers for only about two weeks in every three months.

The blood pressure of the boiler-cleaners taken after exposure were in no case higher than the preexposure readings as might have been expected from the experience of Wyers (1946). In fact they were lower. No explanation is offered for these findings but possibly the men had become accustomed to medical examination by the time the later readings were taken.

Dutton (1911) described vanadium poisoning with symptoms and signs referable to disorders of the gastro-intestinal and renal systems. These were anorexia, nausea, and vomiting, and albumin, blood, and casts in the urine. He also observed anaemia, with a reduction both in the number of cells and of haemoglobin. No cases in the present series had symptoms or signs referable to these systems, though one man did develop a degree of pallor. Symanski (1939) also failed to observe any of these changes. However, two of the boilercleaners developed a fine tremor of the hands, a sign which Dutton and subsequent writers have observed.

In view of the risks of vanadium intoxication involved in cleaning oil-fired boilers, it is suggested that methods of cleaning these boilers should be reviewed and means devised which do not involve exposure to the harmful effects of the petroleum soot. Even intermittent exposures may lead to bronchitis or pneumonia. Men working on these boilers should be under medical supervision. It is probable that much respiratory disease occurs among boiler-cleaners, the true cause of which is not recognized. Finally, it is hoped that this paper may be of some value in drawing attention to the existence of the hazard.

\section{Summary}

Vanadium intoxication in eight men cleaning oil-fired boilers is described.

The method of investigation of the original complaint, the preventive measures instituted, and the results achieved are discussed.

It is suggested that methods of cleaning oil-fired boilers should be reviewed, and that men working on these boilers should be medically supervisied.

I am indebted to Mr. A. T. Wilford, the late superintendent of laboratories, and to Mr. H. E. Styles, present superintendent of laboratories, and their staff for the analyses of the dust and urine; to Mr. H. Branton, Generating Station Superintendent, for his help and cooperation; and to Dr. L. G. Norman, the Chief Medical Officer, for his advice in the preparation of this paper. The thermal precipitator estimations were carried out by the Fuel Research Station, Department of Scientific and Industrial Research.

\section{RFFERENCES}

Dunstan, A. E. (1938). “The Science of Petroleum," vol. 2, p. 1053, London.

Dutton, W. F. (1911). J. Amer. med. Ass., 56, 1648.

Sandell, E. B. (1950). "Colorimetric Determination of Traces of Metals," 2nd ed. (Chemical Analysis, vol. 3.) London.

Sjöberg, S. G. (1949). Nord. Med., 41, 500.

Symanski, H. (1939). Arch. Gewerbepath. Gewerbehyg., 9, 295.
Wyers, H. (1946). British Journal of Industrial Medicine, 3, 177. 